American Journal of Applied Sciences 4 (6): 390-396, 2007

ISSN 1546-9239

(C) 2007 Science Publications

\title{
The Use of Polyethylene in Hot Asphalt Mixtures
}

\author{
Mohammad T. Awwad and Lina Shbeeb \\ Department of Civil Engineering, Faculty of Engineering Technology \\ Marka, P. O. Box. (15008) Amman 11134 Jordan
}

\begin{abstract}
The increase in road traffic during the last two decades in combination with an insufficient degree of maintenance due to shortage in funds has caused an accelerated and continuous deterioration of the road network in Jordan. To alleviate this process, several types of measures may be effective, e.g., securing funds for maintenance, improved roadway design, use of better quality of materials and the use of more effective construction methods. The use of polymer in asphalt mixture as a modifier started in the $80 \mathrm{~s}$ of the last century and has been tested in a number of countries around the World. In this research, polyethylene as one sort of polymers is used to investigate the potential prospects to enhance asphalt mixture properties. The objectives also include determining the best type of polyethylene to be used and its proportion. Two types of polyethylene were added to coat the aggregate [High Density Polyethylene (HDPE) and Low Density Polyethylene (LDPE)]. The polymers were introduced to the mixture in two states (Grinded and not Grinded). Marshall mix design was used, first to determine the optimum bitumen binder content and then further to test the modified mixture properties. In total, 105 samples were prepared (21 samples were used to determine the binder content and the remaining samples were used to investigate the effect of modifying the asphalt mixtures). The optimum asphalt content was 5.4\%. Seven proportions of polyethylene of each type and state by weight of the optimum binder content were selected to be tested $(6,8,10,12,14,16$ and 18\%). The tests include the determination of bulk density, stability and flow. Marshall mix design requires the determination of the percentages of air voids and air voids of mineral aggregate. The results indicated that grinded HDPE polyethylene modifier provides better engineering properties. The recommended proportion of the modifier is $12 \%$ by the weight of bitumen content. It is found to increase the stability, reduce the density and slightly increase the air voids and the voids of mineral aggregate.
\end{abstract}

Key words: Hot asphalt mixtures, polyethylene, optimum binder content, marshal test

\section{INTRODUCTION}

The increase in road traffic during the last two decades in combination with an insufficient degree of maintenance due to shortage in funds has caused an accelerated and continuous deterioration of the road network in Jordan. To alleviate this process, several types of measures may be effective, e.g., securing funds for maintenance, improved roadway design, use of better quality of materials and the use of more effective construction methods. The road network in Jordan has a primarily flexible pavement design. Several factors influence the performance of flexible courses, e.g., the properties of the components (binder, aggregate and additive) and the proportion of these components in the mix. Bitumen can also be modified by adding different types of additive ${ }^{[1,2]}$. One of these additives is the polymers.
The addition of polymers typically increases the stiffness of the bitumen and improves its temperature susceptibility. Increased stiffness improves the rutting resistance of the mixture in hot climates and allows the use of relatively softer base bitumen, which in turn, provides better low temperature performance ${ }^{[3-5]}$. Polymer modified binders also show improved adhesion and cohesion properties.

Polymers can be also added to the asphalt concrete mixtures to form an aggregate coating material. The coatings would enhance surface roughness of the aggregates and thus, produce asphalt mixtures with superior engineering properties ${ }^{[6]}$.

The polymers used in modifying bitumen are classified as plastomers, or elastomers. Plastomers include ethylene vinyl acetate, polyethylene (unstabilized and stabilized) and various compounds based on polypropylene ${ }^{[7]}$. These products may require

Corresponding Author: $\quad$ Lina Shbeeb, Ph. D., Department of Civil Engineering, Faculty of Engineering Technology, Marka, P. O. Box. (15008) Amman 11134 Jordan 
high shear mixing, which depends on the modification process. They increase the viscosity and stiffness of bitumen at normal service temperatures. However, they do not increase the elasticity of bitumen significantly and on heating, they do not perform satisfactory.

Elastomers (rubbers) include natural rubber, polybutadiene, polyisoprene, isobutene-isoprene copolymer, polychloroprene, styrenebutadiene copolymer and styrene-butadienestyrene block copolymer $^{[4]}$. These products are normally milled into the asphalt binder at temperatures above $160^{\circ} \mathrm{C}$ by a high shear mixer. These types of polymers are elastomeric, which describes the ability of a material to return to its original shape when a load is removed. These polymers increase the bitumen viscosity rather than elastomeric strengthening.

In this research the use of polyethylene, which is one type of plastomers, to modify asphalt mix properties was investigated. It is used as aggregate coating rather than modifying bituminous properties. The principle objectives of this research were to:

* Study the effect of adding polyethylene on the hot mix asphalt.

* To identify which type of polyethylene yields the highest material performance.

* To identify the best mechanism of adding the polyethylene to the asphalt mixture to achieve better mixture properties.

* Determine the optimum percent of asphalt and polyethylene in the hot mix asphalt.

\section{MATERIALS AND METHODS}

Bituminous material: Asphalt binder 60/70 was used in this research. The laboratory tests performed to evaluate the bitumen properties were: Specific Gravity, Ductility, Flash Point and Penetration, Softening point. The properties of asphalt binder, which are presented in Table 1, are within the specification of penetrated asphalt grade 60/70.
Aggregate properties: The coarse and fine aggregates used were crushed limestone imported from Amman district of Jordan. The filler used was silica obtained to supplement the fine materials size in hot mix asphat (HMA) mixture design. The laboratory tests performed on coarse aggregates were: Los Angeles Abrasion (ASTM C131 - 81), Aggregate Impact Value, Sieve Analyse (ASTM C136-84) Water Absorption, Specific Gravity (ASTM C127 - 88), Fractured Faces of Aggregate, Chart and Flint Content in Aggregate, Flakiness, Elongation and Angularity (BS 812 812:1989 Part 105 Section 105.1.). The tests for fine aggregates were: sieve Analyse (ASTM C117 - 87) Clay Lumps and Friable Particles in Aggregate (ASTM C142 - 78), Specific Gravity (ASTM C128 - 88) and Water Absorption, while for filler the test was Specific Gravity only. The results of number of tests are shown in Table 2

Ministry of Public Works and Housing (MPW) of Jordan specifications were used to define the mix gradation limits. Several trials were made to combine the coarse, medium and fine hot bin samples to obtain an all-in combined grading satisfying the specification gradation limits as well as providing the appropriate mix properties (Table 2 ).

Polyethylene: Polyethylene is the most popular plastic in the world. Polyethylene is semi-crystalline materials with excellent chemical resistance, good fatigue and wear resistance and a wide range of properties. It has a very simple structure. A molecule of polyethylene is a long chain of carbon atoms, with two hydrogen atoms attached to each carbon atom They are light in weight; provide good resistance to organic solvents with low moisture absorption rates.

Two types of polyethylene grades were used in this research; the mechanical and physical properties are shown in Table 3:

Table 1: Properties of used asphalt binder

\begin{tabular}{lccc}
\hline Test & Test Results & Specification & Minimum \\
\cline { 3 - 4 } & & 1.01 & 1.06 \\
Specific Gravity $\left(\mathrm{g} / \mathrm{cm}^{3}\right)$ & 1.016 & 100 & \\
Ductility $(\mathrm{cm})$ & 132 & 250 & 70 \\
Flash-Point $\left(\mathrm{C}^{\circ}\right)$ & 327 & 60 & 56 \\
Penetration $(0.1 \mathrm{~mm})$ & $(66-70)$ & 46 & 56 \\
Ring-and Ball Softening Point $\left(\mathrm{C}^{\circ}\right)$ & 51 & & \\
\hline
\end{tabular}


Am. J. Appl. Sci., 4 (6): 390-396, 2007

Table 1b: Properties of used aggregate

\begin{tabular}{lccc}
\hline & Coarse Aggregate & Fine Aggregate & Filler \\
\hline Specific Gravity (SG) & 2.78 & 2.92 & 2.912 \\
Water Absorption & $2.65 \%$ & $2.0 \%$ & $2.3 \%$ \\
Impact Test \% & $17 \%$ & & \\
Corrosion percentage: Loss Angeles Test & $30.6 \%$ & & \\
\hline
\end{tabular}

\begin{tabular}{lccccccccc}
\multicolumn{1}{l}{ Table 2: Proposed mix gradation } \\
\hline \% passing & $1^{\prime \prime}$ & $3 / 4^{\prime \prime}$ & $3 / 8^{\prime \prime}$ & No. 4 & No. 10 & No. 20 & No. 50 & No. 100 & No. 200 \\
\hline Proposed Mix & 100 & 100 & 70.5 & 47 & 30.3 & 16.7 & 10.6 & 8 & 5.6 \\
Minimum Limits & 100 & 90 & 80 & 56 & 49 & 34 & 19 & 15 & 2 \\
Maximum Limits & 70 & 53 & 40 & 30 & 23 & 14 & 5 & 4 & 8 \\
\hline
\end{tabular}

Table 3: Mechanical and physical test of polyethylene

\begin{tabular}{llcc}
\hline ASTM/ UL test & Property & LDPE & HDPE \\
\hline D792 & Density $\left(\mathrm{lb} / \mathrm{in}^{3}\right)$ & 0.033 & 0.035 \\
& $\left(\mathrm{~g} / \mathrm{cm}^{3}\right)$ & 0.92 & 0.95 \\
D570 & Water Absorption, 24 hrs $(\%)$ & $<0.01$ & 0 \\
D638 & Tensile Strength (psi) & $1,800-2,200$ & 4,600 \\
D638 & Tensile Elongation at Yield (\%) & 600 & 900 \\
D790 & Flexural Modulus (psi) & - & 200,000 \\
D785 & Hardness, Shore D & D41-D50 & D69 \\
D256 & IZOD Notched Impact (ft-lb/in) & No Break & 3 \\
D696 & Coefficient of Linear Thermal Expansion $\left(\mathrm{x} 10^{-5}\right.$ in./in. $\left./{ }^{\circ} \mathrm{F}\right)$ & 3 & 6 \\
& Heat Deflection Temp $\left({ }^{\circ} \mathrm{F} /{ }^{\circ} \mathrm{C}\right)$ & $120 / 48$ & $105 / 36$ \\
D648 & at 66 psi & $230 / 110$ & $170 / 76$ \\
& at 264 psi & $160 / 71$ & $150 / 40$ \\
D3418 & Approx. Melting Temperature $\left({ }^{\circ} \mathrm{F} /{ }^{\circ} \mathrm{C}\right)$ & & $260 / 125$ \\
- & Max Operating Temp $\left({ }^{\circ} \mathrm{F} /{ }^{\circ} \mathrm{C}\right)$ & $180 / 82$ \\
\hline
\end{tabular}

Low Density Polyethylene (LDPE): it offers good corrosion resistance and low moisture permeability. It can be used in applications where corrosion resistance is important, but stiffness, high temperatures and structural strength.are not

High Density Polyethylene (HDPE): it offers excellent impact resistance, light weight, low moisture absorption and high tensile strength.

The percentages of polyethylene (HDPE, LDPE), that were added to the asphalt mixture that has been designed after determining the optimum bituminous material content ( $5.4 \%$ of mixture weight), were 6,8 , $10,12,14,16$ and $18 \%$ by weight of bitumen content. Three samples for each percent polyethylene were prepared and tested. Adding the polyethylene aimed at providing aggregate coating and not enhancing the bituminous material properties.

Sample preparation: The performance of an asphalt mixture is based on the determination of the correct proportion of aggregate and asphalt and air, which are measured by volume. To determine the optimum bituminous content that would produce a asphalt concrete mixtures with strength and durability properties that meet the MPWH specifications, 21 samples each of 1200 gram in weight were prepared according to the proposed mix design. Three samples were used to prepare asphalt mixtures with one-bitumen content. The average values of three samples for the unit weight, Marshall stability and flow properties for each binder content were determined. Seven binder contents were considered $(4.5,5,5.5,6,6.5,7$ and $7.5 \%$ ). All examined asphalt concrete mixtures were prepared in accordance with the standard 75-blow Marshall design method for designing hot asphalt concrete mixtures, designated as (ASTM Designation: D 1559-89) using automatic compaction.

The optimum bituminous content was $5.4 \%$. Eighty-four samples of asphalt concrete mixtures were prepared at this binder content to test the effect of adding the polyethylene to the mixture. LDPE was added to 42 samples by considering the eight proportions of the polyethylene $(6,8,10,12,14,16$ and $18 \%)$. Three samples were tested for determining the unit weight, stability and flow for each LDPE proportions. The remaining 42 samples were tested by adding HDPE and by considering the same procedure as that of adding LDPE to the mixture. Both types of the polyethylene were added in two states, grinded and un- grinded. The tested samples of each type of polyethylene were divided into two groups. The first group was treated by using the grinded polyethylene 
while the other group was treated by using the not grinded polyethylene.

The procedure of adding the polyethylene is completed by heating the coarse aggregate of each specimen until it reached a $\left(180-190^{\circ} \mathrm{C}\right)$. The heating temperature and duration was chosen based on material characteristics and results of many experimental trials. This temperature is hot enough to melt the polyethylene with a particular size of $2-3 \mathrm{~mm}$ such that it would stick to the aggregate surfaces and leave a textured polyethylene surface with adhesion between the coated aggregates.

\section{RESULTS}

A comparison between asphalt mixture performance due to type and state of the added polyethylene is presented below. The comparison also includes the conventional asphalt mixture (No polyethylene), which acts as the control group.

Bulk density- polyethylene content relationships: The bulk density of the modified asphalt concrete mixtures and regardless of the modified type or state is lower than the conventional asphalt concrete mixture $\left(2.293 \mathrm{gm} / \mathrm{cm}^{3}\right)$. For both types of modifier and at both states of treatment, the maximum bulk density is found when the polyethylene content is around $12 \%$. Although the difference in bulk density due to type and state of the modifier is marginal, asphalt concrete mixture modified with HDPE has highest bulk density $\left(2.28 \mathrm{gm} / \mathrm{cm}^{3}\right)$. The general trend shows that the bulk density increases as the modifier content increases until it reaches the peak that is associated with the highest bulk density. It started to decline significantly afterwards with once exception for the LDPE in grinded state (Fig. 1)

Mixture stability- polyethylene content relationships: Generally, the stability of the modified asphalt concrete mixtures and regardless of the modified type or state is higher than the conventional asphalt concrete mixture - no modifier $(1450 \mathrm{~kg})$. The stability -modifier content relationship varies according to the type of modifier. The highest stability was reported for asphalt mixture that is treated with HDPE grinded modifier $(2347 \mathrm{~kg}$ ), which is higher than mixture treated with the same type of modifier but in not grinded state. The stability of mixtures modified with LDPE in both states fluctuates with no clear trend. Figure 2 shows that the stability asphalt concrete mixture modified by using grinded LDPE is steadily increased by the increase of the modifier content.

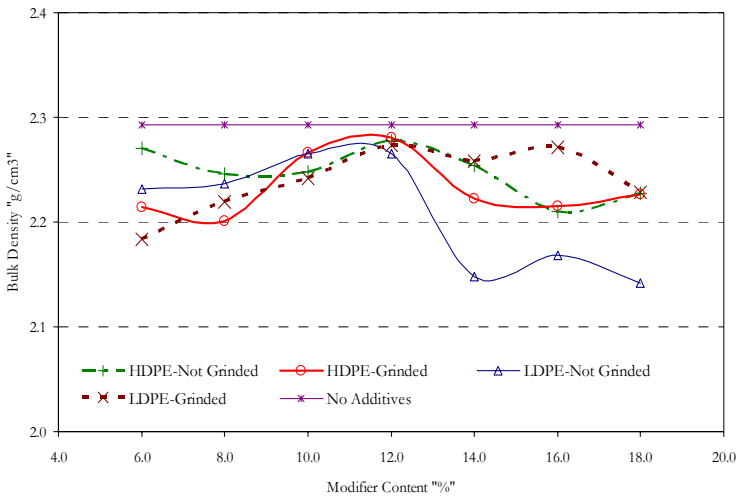

Figure 1: Asphalt mixture unit weight- polyethylene content (modifier) relationship

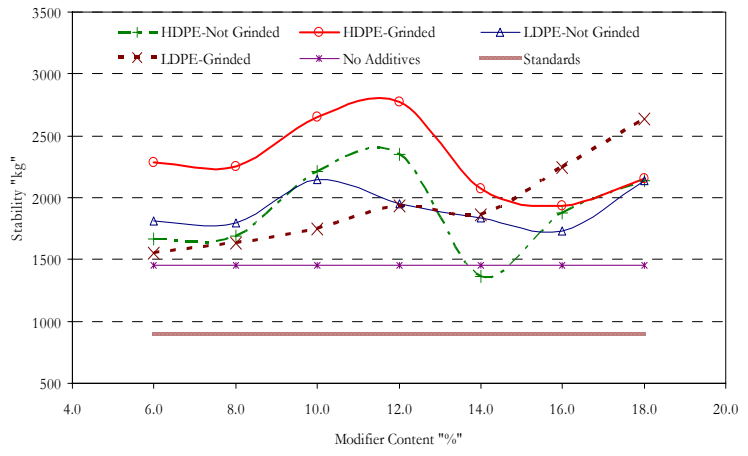

Figure 2: Asphalt mixture stability- polyethylene content (modifier) relationship

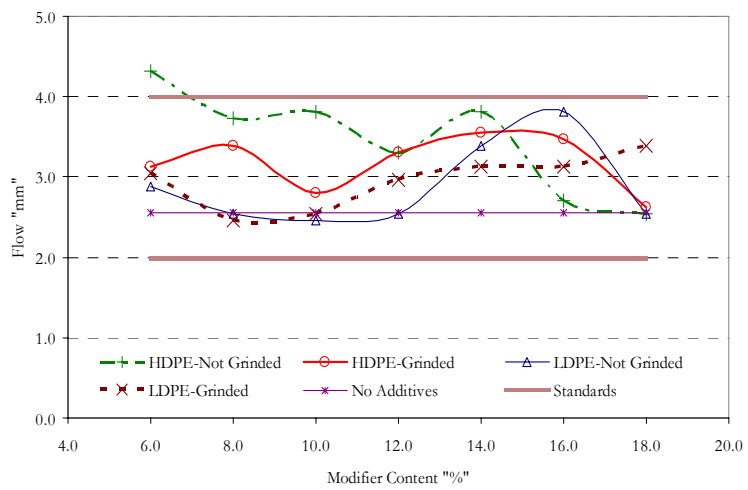

Figure 3: Asphalt mixture flow- polyethylene content (modifier) relationship

Flow- polyethylene content relationships: Generally, the flow of the modified asphalt concrete mixtures and regardless of the modified type or state is higher than the conventional asphalt concrete mixture - no modifier $(2.55 \mathrm{~mm})$. Few exceptions are reported for modified mixtures with $8 \%$ of LDPE measured bitumen weight. The flow-modifier content relationship varies 
according to the type of modifier. The flow of asphalt concrete mixtures modified with HDPE- not-grinded modifier is generally higher than mixtures modified with other forms of modifier. Figure 3 suggests that the flow increases continuously as the proportion of LDPEmodifier content in grinded state increases. This is not the case for other types of modifiers as the flow started to decrease after it reach a peak, which differs according to the modifier type.

Air Void (AV) percentage- polyethylene content relationships: Generally, the AV proportion of the modified asphalt concrete mixtures and regardless of the modified type or state is higher than the conventional asphalt concrete mixture - no modifier $(4.2 \%)$. Asphalt concrete mixture modified with polyethylene of different types and states have AV content that exceeds the standards (specification) of MPWH. Only mixtures modified with modifier content of $12 \%$ by weight of bitumen, regardless of its type, have air voids within the specification. The air void content of asphalt mixtures modified with grinded HDPE approximates the air voids of conventional mixture (no additives). The proportion of air voids in asphalt concrete mixtures modified with polyethylene decreases as the modifier content increases until it reaches the lowest value of air void content and then starts to increase as the modifier increase (Figure 4).

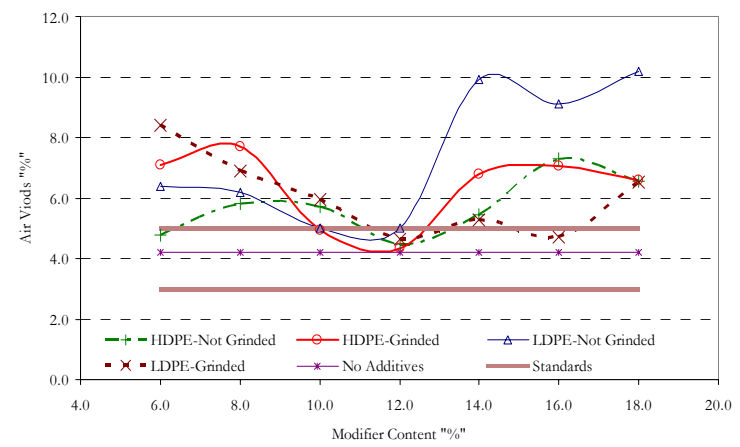

Figure 4: Asphalt mixture air void contentpolyethylene content (modifier) relationship

Void of mineral aggregate (VMA) percentagepolyethylene content relationships: In general, the VMA percentage of the modified asphalt concrete mixtures and regardless of the modified type or state is higher than the conventional asphalt concrete mixtureno modifier $(14.1 \%)$. Asphalt concrete mixture modified with polyethylene of different types and states have air void contents that are with MPWH specifications. Only mixtures modified with modifier content of $12 \%$ by weight of bitumen, regardless of its type, have a minimum VMA contents that approximate the no-additive mixture case (Figue 5). The VMA content of asphalt mixtures modified with grinded LDPE are the lowest among other modified asphalt concrete mixtures. On the other hand, the VMA content of asphalt mixtures modified with not grinded LDPE are the highest among other modified asphalt concrete mixtures.

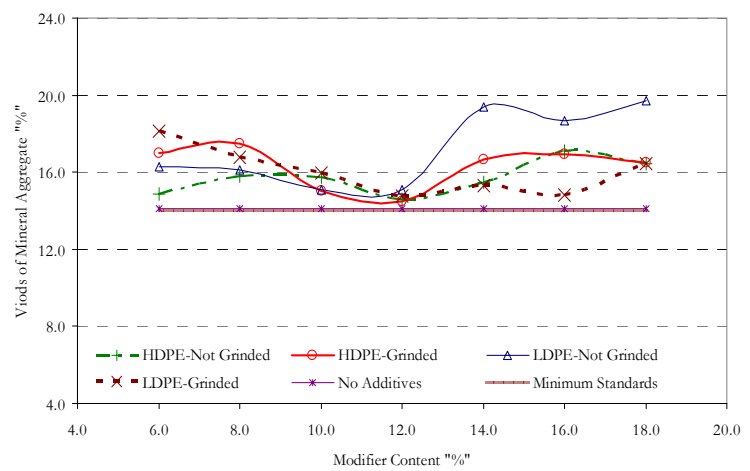

Figure 5: Asphalt mixture voids of mineral aggregate content- polyethylene content (modifier) relationship

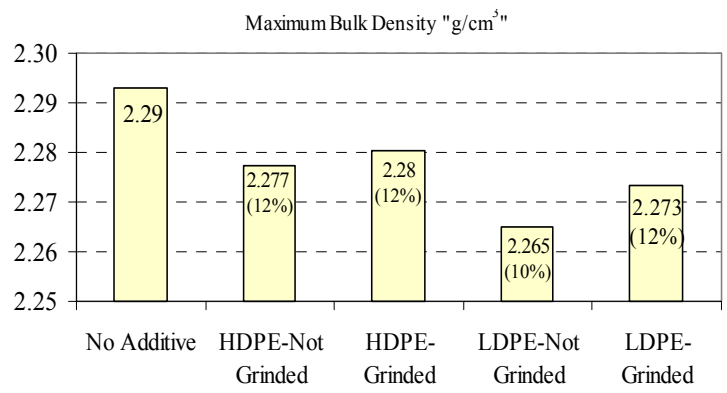

Figure 6: Maximum Asphalt Mixture Bulk Density by Type of Modifier (Number between parenthesis refers to modifier content that provides maximum density)

Optimum modifier content: The optimum modifier content is selected as the content that satisfies the following:

* Maximum Bulk Density

* Maximum Marshall Stability

* Minimum Flow

* The minimum AV or the closet percentage to AV content of $4 \%$

* Maximum VMA content

The maximum bulk density was reported for asphalt mixture modified with grinded HDPE at a 
proportion of $12 \%$ by weight of bitumen content (Figure. 6). In general, mixtures modified with HDPE have a higher bulk density than those modified with LDPE.

The maximum stability $(2775 \mathrm{~kg}$ ) was reported for asphalt mixture modified with grinded HDPE at a proportion of $12 \%$ by weight of bitumen content. Figure 7 shows that mixtures modified with HDPE have a higher stability than those modified with LDPE. Moreover, mixtures modified with grinded polyethylene provided a higher stability compared to those modified with not-grinded polyethylene modifier. The maximum stability of modified mixture with LDPE was reported when the modifier proportion was as low as $10 \%$ measured by weight of bitumen for not-grinded polyethylene and as high as $18 \%$ for grinded polyethylene.

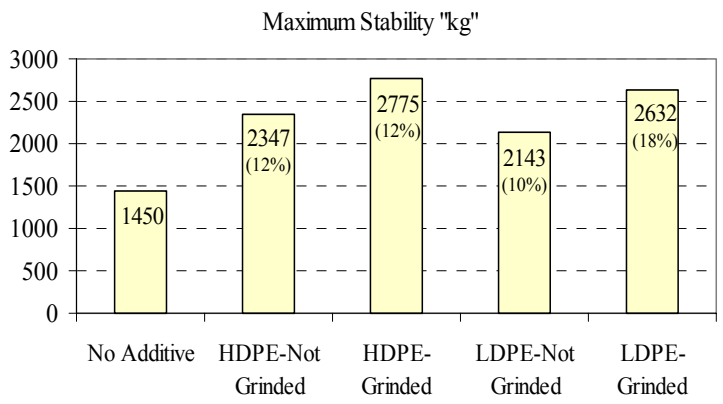

Figure 7: Maximum Asphalt Mixture Stability by Type of Modifier

(Number between parentheses refers to modifier content that provides maximum stability)

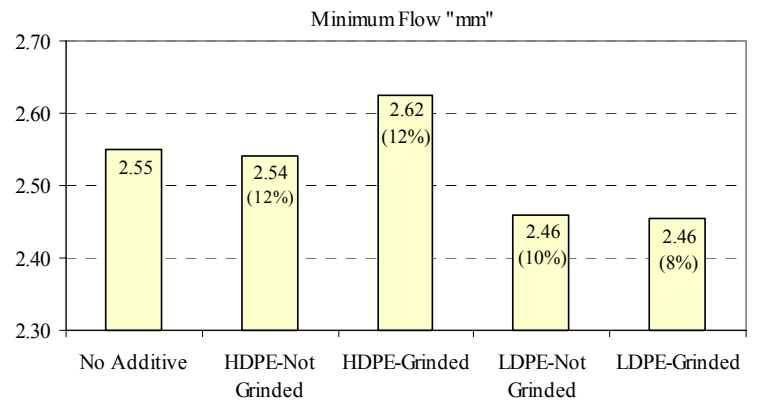

Figure 8: Minimum Asphalt Mixture Flow by Type of Modifier

(Number between parenthesis refers to modifier content that provide minimum flow)

The minimum flow $(2.46 \mathrm{~mm})$ was reported for asphalt mixture modified with LDPE regardless of its state (grinded or not-grinded) at a proportion of 8 and $10 \%$ by weight of bitumen content for grinded and not grinded LDPE respectively. Figure 8 shows that mixtures modified with HDPE have a higher flow than those modified with LDPE. However, it should be noted that the flow for mixture modified with $12 \%$ of HDPE measured by weight, which is associated with maximum bulk density and stability, are within MPWH specification (2-4 $\mathrm{mm})$.

The minimum percentage air void of modified asphalt mixture (4.3\%) was reported for grinded HDPE modifier at a proportion of $12 \%$ by weight of bitumen content, which almost equals to AV of control group (No additive mixtures). Figure 9 shows that mixtures modified with HDPE have a lower AV\% than those modified with LDPE. Moreover, mixtures modified with grinded polyethylene have lower AV percentage compared to those modified with not-grinded polyethylene modifier. The minimum AV percentage of modified mixture with LDPE was reported when the modifier proportion was as low as $10 \%$ measured by weight of bitumen for not-grinded polyethylene $(5 \%)$ and at $12 \%$ for grinded polyethylene with AV of $4.6 \%$.

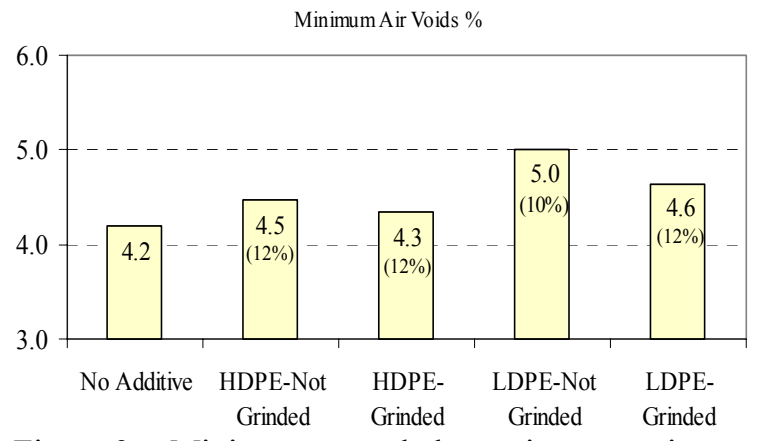

Figure 9: Minimum asphalt mixture air void percentage by type of modifier

(Number between parenthesis refers to modifier content that provide minimum $\mathrm{AV} \%$ )

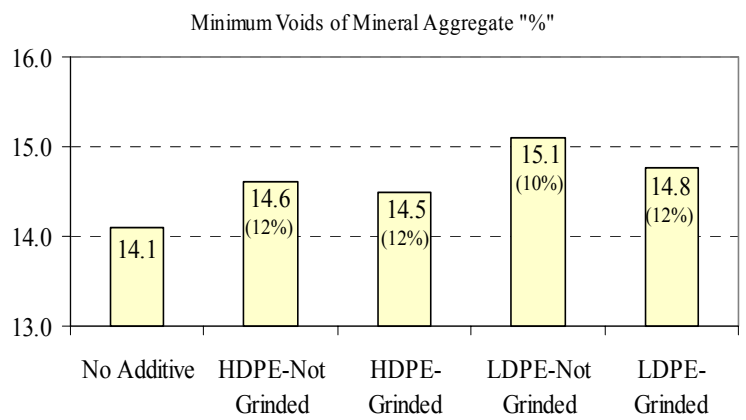

Figure 10: Minimum asphalt mixture vma\% by type of modifier

(Number between parenthesis refers to modifier content that provide minimum VMA\%)

The maximum percentage VMA of modified asphalt mixture (15.1\%) was reported for not-grinded LDPE modifier at a proportion of $10 \%$ by weight of 
bitumen content. The maximum VMA content for other modifiers in other states is always $12 \%$. Figure 10 shows that mixtures modified with HDPE have a lower VMA content compared to mixture modified with LDPE; but the difference is minor. However, it should be noted that the VMA percentage for mixture modified with $12 \%$ of HDPE measured by weight, which is associated with maximum bulk density and stability satisfies MPWH specification (14\% as minimum)

To conclude, it is possible to say is that modifying asphalt mixture with HDPE polyethylene enhances its properties far more than the improvements realized by utilizing LDPE polyethylene. Grinding the polyethylene provide better physical properties. The optimum polyethylene content is $12 \%$ measured by weight of bitumen content. Modifying the mixture with such a proportion is found to provide the highest bulk density, stability and minimum AV percentage and it found to satisfy the specification for the flow and VMA percentage.

\section{DISCUSSION}

By experimentation, the appropriate amount of polyethylene was determined to be (6-18\%) by weight of the optimum asphalt percent $(5.4 \%)$, which equates to $(0.34-1.03 \%)$ by weight of total aggregate. However, the optimum modifier content was found to be $12 \%$, which equals only $0.68 \%$ of the total aggregate weight. This amount did not coat all individual aggregate particles, particularly if it is not grinded. However, it did provide a rougher surface texture that would enhance the asphalt mixtures engineering properties. The grinded polyethylene, providing better coating for the aggregate as the surface area of the polymer increases that would be attached easily to the aggregate.

The results of the study indicated that the modified mixture have a higher stability and VMA percentage compared to the non-modified mixtures. This would positively influence the rutting resistance of these mixtures. The air void contents of the modified mixture are not far from that of the non-modified mixture. Air void proportion around $4 \%$ is enough to provide room for the expansion of asphalt binder to prevent bleeding or flushing that would reduce the skid resistance of the pavement and increase rutting susceptibility.

Overall, using the polyethylene in asphalt mixture reduces pavement deformation; increase fatigue resistance and provide better adhesion between the asphalt and the aggregate.

\section{REFERENCES}

1. Subagio, B.S., et al., 2005. Development of stiffness modulus and plastic deformation characteristics of porous asphalt mmixture using tafpack super, Proceed. Eastern Asia Soc. Transportation Studies, 5: 803-812.

2. Saez-alvan, L.D.P, et al., 2003. Mechanical behavior of asphalt mixtures in regions of low temperature and altitude above 3800 meters, 2003 Int. Conf. Airports: Planning, Infrastructure \& Environ. Rio De Janeiro - RJ-Brazil - June 8 - 11

3. Catt, O.V., 2004. Investigation of polymer modified asphalt by shear and tensile compliances. Material Characterization for Inputs into AASHTO 2002 Guide Session of the 2004 Annual Conf. Transportation Assoc. Canada, Québec City, Québec.

4. Coplantz, J.S. et al., 1993. Review of relationships between modified asphalt properties and pavement performance. SHRP-A-631, Strategic Highway Res. Program, National Res. Council Washington, USA.

5. Newman, K., 2004. Polymer-modified asphalt mixtures for heavy-duty pavements: fatigue characteristics as measured by flexural beam testing, 2004 FAA Worldwide Airport Technol. Transfer Conf. Atlantic City, New Jersey, USA.

6. Kim, M.G., et al., 1999. Coatings to improve lowquality local aggregates for hot mix asphalt pavements. SWUTC / 99 / 167405 - 1, Texas Transport. Inst., Texas A\&M Univ. System

7. Hansen, K.R., et al, Current and future use of nonbituminous components of bituminous paving mixtures. Committee on Characteristics of Nonbituminous Components of Bituminous Paving Mixtures: A2D02. Onlinepubs.trb.org/ onlinepubs/ millennium/00079.pdf 